\title{
APRENDENDO COM A HISTÓRIA: críticas à experiência da Cooperação Norte-Sul e atuais desafios à Cooperação Sul-Sul
}

\author{
Carlos R. S. Milani*
}

\begin{abstract}
O principal objetivo deste artigo é, com base nas limitações críticas apontadas à experiência histórica da Cooperação Norte-Sul (CNS), analisar alguns dos dilemas com que se confrontam as atuais estratégias de Cooperação Sul-Sul.(CSS), concebidas e desenvolvidas por países como Brasil, México, India, China, Turquia ou África do Sul. O autor defende a hipótese de que a diferenciação entre CNS e CSS é fundamentalmente empírica, devendo, porém, também ser pensada à luz do legado do ativismo multilateral de alguns desses países e do novo papel econômico e político que desempenham no cenário internacional. O argumento é construído no sentido de que, por terem sido (e ainda serem) beneficiários da CNS, tais países deveriam atentar para os riscos de reprodução de um modelo de cooperação que eles próprios criticaram no passado recente. O que haveria de singular e distintivo nas práticas de CSS desses países? Quais seriam os riscos de que suas práticas de CSS sejam menos solidárias do que as promessas anunciadas por seus dirigentes e representantes políticos?

PALAVRAS-Chave: Desenvolvimento internacional, Cooperação Norte-Sul, Cooperação Sul-Sul, África do Sul, Brasil, China, Índia, México e Turquia.
\end{abstract}

A cooperação internacional para o desenvolvimento (CID) pode ser definida como um sistema que articula a política dos Estados e atores não governamentais, um conjunto de normas difundidas (ou, em alguns casos, prescritas) por organizações internacionais e a crença de que a promoção do desenvolvimento em bases solidárias seria uma solução desejável para as contradições e as desigualdades geradas pelo capitalismo no plano internacional. Em se tratando de um sistema bastante institucionalizado e complexo na construção de discursos e visões de mundo, a CID envolve inúmeros atores, tanto do lado dos chamados países doadores (tradicionais ou emergentes), quanto no campo dos beneficiários (normalmente países de renda baixa ou, em alguns raros casos, países de renda média). Cada ator apresenta identidade, preferências, interesses e objetivos próprios, podendo agir com base em motivações políti-

* Doutor em Estudos do Desenvolvimento. Professor do Instituto de Estudos Sociais e Políticos (IESP), da Universidade do Estado do Rio de Janeiro (UERJ) e pesquisador visitante do IPEA.

Rua da Matriz, 82 - Botafogo. Cep: 22260-100 - Rio de Janeiro, RJ - Brasil. crsmilani@iesp.uerj.br cas, de segurança nacional, por razões humanitárias ou morais, mas também por motivos econômicos e ambientais.

No entanto, não devemos esquecer que o conjunto das relações entre os dois tipos de atores (doadores e beneficiários) também é reflexo da economia política internacional, ou seja, das assimetrias e hierarquias existentes entre o centro e a periferia, entre o Norte e o Sul do sistema internacional. Além disso, entre doadores (tradicionais e novos) e beneficiários situam-se "atores-mediadores", que desempenham papel relevante na difusão das agendas, na legitimação dos ideários e, menos frequentemente, na organização de protestos e na definição de mecanismos de monitoramento e controle. Agem nesse sentido muitas organizações não governamentais, movimentos sociais, redes de ativismo político, a mídia internacional e alguns centros de pesquisa.

Embora não haja um único arquiteto responsável pela fundação, manutenção e evolução da CID, o atual sistema da cooperação tem suas origens, majoritariamente, nas iniciativas norteamericanas logo após a segunda grande guerra. Foi 
nesse momento histórico que se abandonou uma lógica de ajuda pontual a nações em situação de emergência em prol de uma dinâmica cada vez mais permanente e institucionalizada de cooperação para a transformação das estruturas produtivas, administrativas, sociais e culturais das sociedades beneficiárias dos financiamentos e dos projetos de assistência técnica. O que, no século XIX e meados do século $\mathrm{XX},{ }^{1}$ fora iniciado enquanto ajuda alimentar de urgência e como expediente diplomático de natureza temporária passou a se constituir em padrão normativo nas relações entre Estados, agências internacionais e organizações não governamentais. Dito de outra forma, com a guerra fria se institucionalizou e se legitimou o multilateralismo da cooperação para o desenvolvimento. ${ }^{2}$ Carol Lancaster afirma que "ao final da Segunda Guerra Mundial, a ajuda internacional, tal como a conhecemos nos dias de hoje, não existia (...). Se não tivéssemos vivido as ameaças da guerra fria, os Estados Unidos nunca teriam iniciado seus programas de ajuda internacional" (Lancaster, 2007, p.1-3, tradução nossa). A política de competição entre a URSS e os EUA e a ameaça comunista foram, desse modo, fatores decisivos para o processo de institucionalização da CID. Os antecedentes da CID relacionados à em-

${ }^{1}$ Não foram poucas as iniciativas de cooperação internacional que se viram diretamente influenciadas pelo contexto político da colonização e pela tentativa de, em nome do desenvolvimento, transferir modelos econômicos, institucionais ou até mesmo culturais das metrópoles para as colônias. Em 1940, o British Colonial Development and Welfare Act permitiu o financiamento de projetos de desenvolvimento social e acentuou a intervenção direta da Coroa britânica nos programas locais de educação. Isso se deu, principalmente, graças à crença de que tais tipos de investimentos, de natureza sociocultural, ajudariam a preparar uma elite entre os colonizados (principalmente africanos) que seria posteriormente chamada a integrar os aparelhos administrativos na gestão das colônias. Inicialmente, nos anos 1920, haviam sido investidos valores estimados em um milhão de libras anuais, que chegaram a aproximadamente cinco milhões no ano de 1940 e

120 milhões em 1945. Em 1947, a lei conhecida como Overseas Development Act criou uma instituição, a Colonial Development Corporation, cuja função era coordenar tais projetos nas colônias britânicas, além da Overseas Development Corporation, a fim de promover a cooperacão para o desenvolvimento em outros Estados soberanos (Olutayo et al, 2008).

${ }^{2}$ Houve cooperação entre o bloco soviético e países em desenvolvimento (nos casos do Egito, da India, por exemplo), porém a institucionalizaçẫo foi mais avançada e organizada no campo liberal ocidental; é dela que falamos ao tratar da CID no momento pós-segunda guerra. presa colonial, à emancipação política africana e asiática, bem como à disputa ideológica Leste-Oeste confirmam que as noções de "cooperação internacional" e "desenvolvimento" acompanham a própria história do sistema econômico capitalista, do projeto universalizante de modernização das sociedades e do liberalismo multilateral nas relações internacionais. Ambas as noções de "cooperação internacional” e "desenvolvimento" encontram suas fundações no ideal de progresso econômico e solidariedade social, bem como na necessidade de construção de amplos consensos políticos entre as nações. Gilberto Dupas lembra que a busca do progresso justificou ações políticas com base em um atestado de que nos estaríamos tornando uma sociedade melhor, mais justa e, por que não dizer, mais "civilizada”. No entanto, o progresso se tornou um mito ao apontar a marcha à frente, uma movimentação com direção definida, um desenvolvimento da ordem e a realização de um mundo cada vez mais próximo da perfeição, porém sem dizer o sentido desse movimento ou explicitar a perspectiva daqueles que o comandam e a dos que são comandados (Dupas, 2006). Em nome da cooperação internacional e da promoção do desenvolvimento têm sido difundidas visões políticas, por vezes redutoras das contradições e das assimetrias entre as classes sociais, as sociedades, as nações e a economia internacional, mas também têm sido perpetradas ingerências de natureza cultural, social, econômica e política.

Neste artigo, pretendemos discutir as limitações críticas apontadas à experiência histórica e às agendas mais recentes da Cooperação Norte-Sul (CNS), a fim de lançarmos questionamentos acerca dos dilemas que poderão cruzar (ou que, talvez, já estejam cruzando...) as estratégias de Cooperação Sul-Sul (CSS) concebidas e desenvolvidas por países como o Brasil, México, Índia, China, Turquia ou África do Sul. ${ }^{3}$ Defendemos aqui a hipótese de que a diferenciação entre CNS e CSS é fun-

${ }^{3}$ Uma descrição mais detalhada do nosso atual projeto de pesquisa, "Cooperação Sul-Sul e Agendas de Política Externa em Perspectiva Comparada: África do Sul, Brasil, China, Índia, México e Turquia”, com apoio do IPEA, pode ser encontrada em www.labmundo.org. 
damentalmente empírica. É evidente que a CSS deve ser pensada à luz do legado histórico do ativismo multilateral dos países em desenvolvimento (G-77, nova ordem econômica internacional, não alinhamento), dos processos de transformação do sistema internacional desde os anos 1990, mas igualmente em função das necessidades de ajuste por que passa o capitalismo (com as crises de meados dos anos 1990, na periferia do sistema, e a partir de 2007, no seu centro). No entanto, diferenciar CSS de CNS implica, metodologicamente, ir além da análise das promessas e dos discursos dos governos dos países em desenvolvimento, das denúncias e propostas de parcerias dos atores não governamentais. Implica conhecer a realidade dos países em que os projetos de CSS estejam em curso, pensar seus impactos também na perspectiva do "outro" que é beneficiário da cooperação prestada, ou seja, do moçambicano, do angolano, do haitiano, etc. Defendemos o argumento de que, por serem países que também se beneficiaram (e ainda se beneficiam) da CNS, África do Sul, Brasil e Índia, entre outros, deveriam atentar para os riscos de reprodução de um tipo de experiência (a cooperação “top-down”, "colonizadora”, não participativa, etc.) que eles próprios criticaram no passado recente. De países beneficiários a doadores cada vez mais relevantes (doadores "emergentes", segundo a $\mathrm{OCDE}^{4}$ ), o que países de renda média ou "novas potências" (Narlikar, 2010) como Brasil, Índia ou China propõem de distintivo em suas práticas de CSS? Quais seriam os riscos de que suas políticas de CSS sejam menos solidárias do que as promessas anunciadas e que venham a

4 De fato, a OCDE foi ator-chave no processo de institucionalização histórica da CID, uma vez que logrou mobilizar distintos países doadores e organizações multilaterais em torno da necessidade de harmonização dos conceitos e de coordenação das políticas. Um dos primeiros passos do CAD foi a formulação de um conceito de ros passos do CAD foi a formulação de um conceito de o desenvolvimento constitui-se de fluxos financeiros remetidos aos países e territórios que constam da lista de beneficiários do CAD da OCDE e às instituições multilaterais de desenvolvimento (Grupo Banco Mundial, PNUD, UNICEF, bancos regionais, etc.), desde que sejam oficiais (ou seja, prestados por governos, centrais ou locais, e por agências públicas), destinados à promoção do desenvolvimento econômico e do bem-estar das sociedades dos países em desenvolvimento, e concedidos a fundo perdido (sem gerar a obrigação de reembolso) em pelo menos $25 \%$ do total enviado. Fonte: www.oecd.org. seguir primordialmente estratégias comerciais e de investimento, com base principalmente em interesses econômicos nacionais e na tentativa de obtenção de recursos minerais ou de acesso a mercados para suas "commodities" e bens manufaturados?

\section{OS ANOS 1990: tendências recentes da agenda de negociações da CNS}

Os anos 1990, marcados pelo fim da ordem bipolar, pela aceleração dos processos de globalização e democratização das relações Estado-sociedade em vários contextos nacionais, prometiam um mundo mais pacífico em que a cooperação para o desenvolvimento seria prioritária. Pelo menos retoricamente, era nesse sentido que convergiam dois dos principais relatórios produzidos pelo então SecretárioGeral das Nações Unidas, Boutros Boutros-Ghali: a Agenda para a Paz (de 1992) e a Agenda para o Desenvolvimento (de 1994). ${ }^{5}$ Nesse contexto, os seguintes aspectos passaram a receber maior atenção na agenda da CID: combate contra a disseminação de pandemias (ébola, SARS, gripe aviária), proteção da biodiversidade e fenômeno das mudanças climáticas, descentralização e desenvolvimento local, parcerias entre os setores público e privado (incluindo a atuação do chamado Terceiro Setor), programas de minoração da pobreza e difusão das microfinanças. ${ }^{6}$

Não menos relevantes foram os programas relativos à gestão da interdependência no mundo globalizado, tais como a aceleração das políticas de convergência econômica entre países em desenvolvimento e industrializados, políticas de "boa governança”, de equilíbrio macroeconômico e de redução da dívida externa. Os países da OCDE passaram a redirecionar seus fundos, de forma

${ }^{5}$ Conferir Nações Unidas, Assembleia Geral, "An agenda for development", documento A/48/935, 6 maio 1994. Ver também: http://www.undemocracy.com/A-49665.pdf

6 Sobre a disseminação das agendas relativas ao microcrédito, conferir: KRAYCHETE, Elsa Sousa. Banco Mundial e o Desenvolvimento das Microfinanças em Países da Periferia Capitalista. Salvador, Universidade Federal da Bahia, Tese de Doutorado, 2005 (disponível em www.adm.ufba.br). 
prioritária, para a Europa oriental e as chamadas "economias em transição". Como resultado das prioridades então definidas pelos principais doadores bilaterais e multilaterais, reduziram-se os projetos de ajuda alimentar e reforçaram-se os financiamentos setoriais e programáticos. Passouse a dar maior ênfase aos diálogos sobre políticas públicas ("policy dialogues"), ao critério da seletividade (com foco nas políticas econômicas) e a programas de formação (“capacity-building”). É evidente que a ideologia dos mercados livres e do Estado mínimo serviu de tela de fundo para essa nova agenda da cooperação.

Portanto, a agenda da CID encontrava-se claramente ampliada: de projetos e intervenções pontuais os principais doadores passaram a privilegiar programas (com metas e estratégias) e políticas, aumentando significativamente a envergadura temática e o raio de ação da cooperação para o desenvolvimento. Da "ajuda internacional" passouse à lógica de cooperação e parcerias (DegnbolMartinussen; Engberg-Pedersen, 2008). Enquanto o espectro da agenda foi sendo ampliado, avançando para questões relativas à reforma do Estado, a orientação estratégica foi de "focar" os projetos em grupos de beneficiários (os mais vulneráveis, os mais pobres, etc.), como sintetiza o Quadro 1.

Além disso, poderíamos dizer que três temas principais estiveram no centro das atenções da CID. Em primeiro lugar, após décadas de suprema- cia da renda per capita como indicador exclusivo do desenvolvimento (medindo, de fato, o crescimento econômico), o PNUD lança o indicador do desenvolvimento humano (IDH) como o novo parâmetro integrador das dimensões da saúde e da educação com a lógica do crescimento (PNUD, 1990). Foram considerados fundamentais na construção do IDH: a expectativa de vida longa e com saúde, a alfabetização e o acesso aos diversos níveis de educação formal, bem como a disponibilidade de recursos econômicos (renda) para ter-se uma vida humanamente digna. Pode-se afirmar que, apesar de suas limitações (ao desconsiderar, entre outros aspectos, a problemática ecológico-ambiental) e das distorções produzidas (por exemplo, a concorrência desenfreada entre Estados por melhores classificações no ranking mundial do IDH), o desenvolvimento humano inaugurou uma tendência de fundo que nos parece crucial nas agendas da cooperação, porquanto contribuiu sobremaneira para institucionalizar discursos multidimensionais e disseminar visões mais abrangentes sobre o desenvolvimento. É bem verdade que, ao mesmo tempo, corroborou uma noção mais nacionalizada e individual (sedimentada nas capacidades de cada pessoa) do desenvolvimento, colocando para escanteio o debate estrutural e político sobre as desigualdades entre países ou regiões e as diferenças de classes sociais na ordem internacional.

Em segundo lugar, poderíamos lembrar os

Quadro 1: Expansão do escopo da CID (tipo e nível das intervenções)

\begin{tabular}{|c|c|c|c|c|c|}
\hline $\begin{array}{l}\text { Tipos de } \\
\text { intervenção }\end{array}$ & Nível social privilegiado & $\begin{array}{l}\text { Anos } \\
1960\end{array}$ & $\begin{array}{r}\text { Anos } \\
1970\end{array}$ & $\begin{array}{l}\text { Anos } \\
1980\end{array}$ & $\begin{array}{l}\text { Anos } \\
1990\end{array}$ \\
\hline \multirow{3}{*}{ Políticas } & $\begin{array}{l}\text { Nível político do Estado: reformado poder judiciário, sistema político de } \\
\text { partidos, parlamentos, programas de governança pública }\end{array}$ & & & & \\
\hline & $\begin{array}{l}\text { Administração pública central: ministérios econômicos e relacionados } \\
\text { com o planejamento e finanças }\end{array}$ & & & & \\
\hline & $\begin{array}{l}\text { Administração pública: ministérios não econômicos, } \\
\text { conselhos nacionais e empresas estatais }\end{array}$ & & & & \\
\hline \multirow{3}{*}{ Programas } & $\begin{array}{l}\text { Economia nacional: política macroeconômica, privatização, reformas } \\
\text { econômicas e apoio ao setor privado }\end{array}$ & & & & \\
\hline & $\begin{array}{l}\text { Administrações locais: conselhos de gestão, descentralização } \\
\text { da administração pública nacional }\end{array}$ & & & & \\
\hline & $\begin{array}{l}\text { Economia nacional: desenvolvimento agrícola, pesquisa sobre tecnologias } \\
\text { voltadas para a modernização do campo e setor informal }\end{array}$ & & & & \\
\hline \multirow{2}{*}{ Projetos } & $\begin{array}{l}\text { Organizações da sociedade civil, associações nacionais, cooperativas } \\
\text { regionais e nacionais }\end{array}$ & & & & \\
\hline & $\begin{array}{l}\text { Grupos individuais, grupos comunitários, domicílios, associações de } \\
\text { bairro }\end{array}$ & & & & \\
\hline
\end{tabular}

Fonte: Adaptado a partir de Degnbol-Martinussen; Engberg-Pedersen (2008, p. 40). 
temas globais como tendência importante dos anos 1990/2000. As diferentes conferências da ONU colocaram em evidência a educação (Jomtien em 1990), a proteção ambiental (Rio de Janeiro em 1992), os direitos humanos (Viena em 1993), os direitos reprodutivos e a demografia (Cairo em 1994), os direitos da mulher e a problemática do gênero (Beijing em 1995), o desenvolvimento social (Copenhague, 1995), a gestão urbana e a internacionalização das cidades (Istambul em 1996), bem como a discriminação racial (Durban, 2001). Permitiram o debate sobre um mosaico de posições e realidades do Norte, do Sul, do Ocidente e do Oriente, entre mundos culturais e religiosos diversos, além de difundirem essas agendas em diferentes geografias do planeta. Apesar de muito amplas e frequentemente presas à necessidade de produzir consensos excessivamente abrangentes sobre temas delicados e profundos do ponto de vista cultural, filosófico e político, as conferências da ONU contribuíram para expandir as estratégias de monitoramento, ensejando a criação de redes transnacionais, envolvendo inclusive movimentos sociais e organizações não governamentais, que passaram a funcionar como verdadeiros radares da cooperação para o desenvolvimento.

Um terceiro aspecto que poderíamos destacar nas agendas da CID nos anos 1990/2000 diz respeito aos Objetivos do Milênio, popularmente conhecidos como ODM. Conjunto de metas acompanhadas de indicadores de monitoramento e avaliação, os ODM passaram a ocupar o centro das atenções de governos, organizações internacionais e não governamentais, entidades filantrópicas e, inclusive, de personalidades do mundo midiático, a exemplo de Bono Vox, Brad Pitt ou Angelina Jolie $^{7}$. Ademais de toda a busca de midiatização que chegou inclusive a levar os ODM a shopping centers, foram legitimados por conferências da própria ONU, a exemplo da que foi realizada em Monterrey, no México, em 2002, quando governos do Norte e do Sul reconheceram que os mon-

${ }^{7}$ Uma apresentação institucional dos ODM pode ser encontrada em http://www.pnud.org.br/odm, bem como em http://www.objetivosdomilenio.org.br. tantes destinados à CID ainda se situavam em patamares muito aquém do necessário para que as mazelas do subdesenvolvimento pudessem ser superadas. Também foram reforçados a partir do lançamento do "Global Compact", programa de parcerias entre Estados, organizações intergovernamentais (ONU) e empresas transnacionais. Aspecto crucial dos ODM, e que se relaciona estreitamente com o conceito de desenvolvimento humano apresentado anteriormente, a agenda de cooperação por eles defendida visa a melhorar principalmente as condições de desenvolvimento do indivíduo. O foco, uma vez mais, deixa de ser o âmbito nacional, estrutural e coletivo, direcionando-se para o bem-estar individual, em pleno acordo com o ideário liberal.

Após os atentados de 11 de setembro de 2001, ocorreram algumas importantes inflexões na política vigente em matéria de CID: muitos governos e agências, a reboque das decisões e necessidades do governo norte-americano, passaram a priorizar as estratégias de segurança e o combate contra as diferentes manifestações de terrorismo transnacional. A política da segurança ganhou terreno diante de ideia de cooperação técnica, econômica, intelectual e cultural, ameaçando o próprio ideal do multilateralismo. Com a implementação de uma agenda mais repressiva e de controle, algumas questóes correlatas à CID, por exemplo com respeito às remessas de migrantes a suas comunidades de origem, passaram a ser interpretadas e reguladas não sob a ótica da cooperação e do desenvolvimento, mas na perspectiva bastante realista da segurança das fronteiras nacionais. Isso tudo apesar da importância dos montantes envolvidos: somente os migrantes trabalhando na Europa enviam para a região da África do Norte cerca de 10 bilhões de euros por ano (Severino; Ray, 2009, p.14). Estima-se que o total das remessas de migrantes para os países em desenvolvimento tenha passado de 74 bilhões de dólares US em 2000 para cerca de 200 bilhões em 2007, salientando-se o caso de países tais como o México, Filipinas, Índia, Egito, Turquia e Bangladesh. Em 2010, somente no caso dos países em desenvolvimento, chegaram a 325 bilhões, devendo atingir a cifra de 
aproximadamente 404 bilhões em 2013, segundo as previsões do Banco Mundial. ${ }^{8}$

Em paralelo à securitização das agendas, a qualidade e a eficácia da ajuda internacional passaram a ser objeto de crescente preocupação dos doadores. Duas declarações (Paris em 2005 e Acra em 2008) enfatizaram a noção de eficácia da ajuda internacional para o desenvolvimento, buscando analisar seu impacto em relação ao que se convencionou chamar de ajuda fantasma. Para que a CID seja eficaz, deve dar prioridade ao desenvolvimento de capacidades nacionais, garantir a apropriação pelos países em desenvolvimento ("ownership"), coordenar os programas e projetos dos diversos doadores bilaterais e multilaterais com os objetivos das políticas públicas dos países beneficiários ("alignment"), reforçar a responsabilidade mútua, implementar ferramentas de gestão por resultados e, finalmente, harmonizar as práticas e estratégias dos Estados-doadores (“harmonization"). Isso foi o que afirmaram, em linhas gerais, ambas as declarações.

Com relação ao surgimento dos chamados "novos atores", rompeu-se definitivamente o monopólio dos Estados na CID. Klein e Harford (2005) referem-se a um verdadeiro "mercado para a ajuda" (2005), uma vez que atores e mecanismos privados trazem a tradição, a ética e as práticas do mercado para o mundo da cooperação. É evidente

${ }^{8}$ Dados a partir do Banco Mundial (Outlook for Remittance Flows 2011-2013), publicados em maio de 2011 pela Migration and Remittances Unit (Migration and Development Brief 16). Conferir também os dados disponíveis em www.migrationinformation.org. porém com menos autonomia política e maior dependência de recursos governamentais.

No caso das fundações oriundas das grandes corporações, devemos salientar o papel da Fundação Bill e Melinda Gates, que tem um capital de 70 bilhões com um orçamento anual planejado de 6 bilhões de dólares, tendo-se tornado atorchave na governança dos problemas de saúde global (vacinas, por exemplo). Ademais, novos fundos e mecanismos têm sido desenvolvidos: GAVI (Global Fund against AIDS), UNITAID (criado em 2006, para combater a disseminação do HIV/AIDS, da malária e da tuberculose), Mecanismo de Desenvolvimento Limpo (no âmbito do Protocolo de Kyoto), GEF (Global Environmental Facility, criado no bojo da Rio-92), entre outros. Também há doadores estatais emergentes, com discursos e projetos de CSS que pretendem ser distintos em suas práticas da experiência da CNS.

Ou seja, o cenário da cooperação é bastante mais complexo e multifacetado. Tornam-se cada vez mais porosas as fronteiras entre a solidariedade pública e privada. Países beneficiários passam também a definir suas agendas enquanto países doadores, tal como tem ocorrido no caso do Brasil, da África do Sul, da Índia, do México, da Turquia ou ainda da China. A fragmentação também faz parte das críticas possíveis: 80 mil novos projetos a cada ano, financiados por pelo menos 42 países doadores por meio de 197 agências bilaterais e 263 organizações multilaterais (Kharas, 2010, p.4). Também resulta desse cenário a necessidade ainda maior de coerência e coordenação: somente o Camboja teria recebido cerca de 400 missões de doadores por ano, em média, ao passo que a Nicarágua teria recebido 289 missões e o Bangladesh, 250 (Severino; Ray, 2009, p.6). Não menos relevante é a crítica feita por Kharas (2010) no sentido de que as boas experiências no nível de projetos não repercutem, automática e necessariamente, no plano macroeconômico. Outro problema destacado na agenda atual: a AOD e as políticas de comércio, de investimento e migrações geram interdependências que ainda são pouco analisadas nos estudos acadêmicos e no debate político. 
É nesse contexto crítico da CNS (e do capitalismo) que se evidencia, cada vez mais, a relevância apontada da CSS no sistema da cooperação internacional para o desenvolvimento.

\section{COOPERAÇÃO INTERNACIONAL PARAO DESENVOLVIMENTO: interpretações e leituras críticas}

As perspectivas sobre a cooperação para o desenvolvimento não são consensuais. Existem visões favoráveis e outras mais críticas quanto à sua natureza, seus objetivos e resultados, ou ainda quanto aos efeitos econômicos, tecnológicos, sociais, culturais, ambientais e políticos por ela engendrados. Ambos os tipos de visões compartilham da ideia de que a força do discurso sobre o desenvolvimento é proporcional à sedução por ele exercida, sedução no sentido de "agradar, fasci- nar, iludir, mas também abusar, desviar da realidade, enganar" (Rist, 1996, p. 9). Samuel Huntington (1970, p.186) afirmou que seriam quatro as fontes intelectuais da crítica à CID: o nacionalismo (a CID como ingerência), o socialismo (a CID como expressão hegemônica do capitalismo), o tradicionalismo (a defesa das tradições contra a modernização desenvolvimentista) e o antiocidentalismo (o embate contra o etnocentrismo da cooperação). O Quadro 2, a seguir, esquematiza essas posições, sobretudo a partir das Relações Internacionais.

A posição do liberalismo pode ser considerada ambivalente. Por um lado, adotando a premissa de que os agentes (indivíduos, Estados) são racionais e, portanto, capazes de cooperar, alguns liberais adotariam a noção de regime para interpretar a CID, ${ }^{9}$ apresentando como seu princípio maior a prática da cooperação econômica como uma política racional. Com base no dever moral de aju-

Quadro 2 - Visões sobre a cooperação internacional para o desenvolvimento

\begin{tabular}{|c|c|c|}
\hline Perspectivas & Visões pró-cooperação & Visões céticas e criticas \\
\hline $\begin{array}{l}\text { Micro: } \\
\text { - implicações } \\
\text { para os países } \\
\text { doadores e os } \\
\text { beneficiários }\end{array}$ & $\begin{array}{l}\text { Promove o crescimento e o desenvolvimento } \\
\text { dos países beneficiários (visão liberal em sua } \\
\text { vertente mais idealista). }\end{array}$ & $\begin{array}{l}\text { O crescimento e o desenvolvimento resultam de } \\
\text { esforços endógenos, a partir das capacidades, recursos } \\
\text { e atores que podem ser encontrados nos próprios } \\
\text { contextos locais de cada nação (teoria da } \\
\text { dependência). }\end{array}$ \\
\hline $\begin{array}{l}\text { Macro: } \\
\text { - implicações } \\
\text { para a política } \\
\text { internacional }\end{array}$ & $\begin{array}{l}\text { Promove a integração (comercial, econômica), } \\
\text { paz e prosperidade nas relações entre países } \\
\text { doadores e beneficiários (visão liberal } \\
\text { institucionalista). Os países mais ricos têm o } \\
\text { dever moral e humanitário de ajudar os } \\
\text { menos desenvolvidos (visão liberal idealista). } \\
\text { Contribui para a construção e difusão de } \\
\text { valores e normas (direitos humanos, proteção } \\
\text { ambiental, democracia, equidade de gênero, } \\
\text { etc.) e a socialização dos Estados nesse } \\
\text { âmbito (visão construtivista) }\end{array}$ & $\begin{array}{l}\text { CID como interferência dos Estados e governos no } \\
\text { mundo dos mercados, dos investimentos, do } \\
\text { comércio, que seriam os fundamentos reais do } \\
\text { desenvolvimento das nações (visão ultraliberal). CID } \\
\text { como expressão mais ou menos sutil das } \\
\text { desigualdades do sistema interestatal capitalista e do } \\
\text { imperialismo, sustentando relações assimétricas entre } \\
\text { países desenvolvidos e em desenvolvimento (visão } \\
\text { marxista). Cooperação bilateral como expressão dos } \\
\text { interesses da política externa do país doador, podendo } \\
\text { configurar uma política estratégica de dominação, } \\
\text { alinhamento, soft power ou neocolonialista (visão } \\
\text { réalista). }\end{array}$ \\
\hline
\end{tabular}

Fonte: A partir de Pankaj (2005, p. 105)

${ }^{9}$ Lembramos aqui o conceito de regime proposto por Stephen Krasner, segundo o qual o regime é uma forma de construção da ordem internacional que se inicia quando seus membros respeitam ou se referem a seus aspectos principais, suas normas e princípios. Os regimes são variáveis intermediárias e externas (intervening variables) entre fatores de causalidade primária (poder, interesse estratégico) e elementos relativos a resultados e comportamentos dos atores internacionais. O regime é, assim, mais que um conjunto de regras, pressupondo um nível elevado de institucionalização; ele é integrado por quatro ele- mentos principais: princípios (como o mundo deve funcionar), normas (para orientar os comportamentos, definir direitos e deveres), regras (ferramentas de resolução dos conflitos, têm caráter mais instrumental) e procedimentos de tomada de decisão (sistema de votação, por exemplo). Vide: KRASNER, Stephen D. Structural causes and regime consequences: regimes as intervening variables. International organization, v.36, n.2, 1982; LITTLE, Richard. International Regimes, BAYLIS, John; SMITH, Steve (Org.) The globalization of world politics. Oxford: Oxford University Press, 2001. p.299-316. 
dar os países menos desenvolvidos, a cooperação seria portadora de um ideal de justiça social e de abertura para o "outro", estando fundamentada em uma verdadeira ética do desenvolvimento (Gottsbacher; Lucatello, 2008). A cooperação para o desenvolvimento resultaria da crescente necessidade, para os Estados, de responderem aos problemas gerados pela "interdependência complexa" (Keohane; Nye, 2000) e, nesse sentido, de produzirem bens públicos globais ou regionais (Kaul et al, 1999, 2003). A CID seria uma forma de gestão dos riscos sociais, agora cada vez mais globais e produziria alguns benefícios que, segundo o neoinstitucionalismo liberal, seriam notáveis: (i) redução dos custos de transação para negociar e manter acordos; (ii) estabelecimento do ideal da reciprocidade e do princípio da previsibilidade; (iii) circulação de informação para tornar as preferências mais transparentes; (iv) definição de padrões de comportamento e institucionalização de mecanismos de sanção, além da obtenção de vantagens coletivas.

Outros analistas e pensadores ultraliberais (Friedrich Von Hayek, Milton Friedman, Peter Bauer, Frances Moore Lappé) sustentariam a hipótese de que a ajuda internacional deveria ser considerada como um obstáculo que retarda o desenvolvimento das nações e a auto-organização dos mercados. Seria uma prática de intervenção estatal que tem tornado os pobres ainda mais pobres, beneficiado de- base na emoção do que na razão (Moyo, 2010). ${ }^{10}$

Os construtivistas tenderiam a enfatizar que a CID seria, ela própria, um padrão resultante das relações de socialização entre os Estados. Por meio da interação cooperativa gera-se conhecimento compartilhado e criam-se instituições e regras facilitadoras da prática e da aprendizagem da cooperação para o desenvolvimento. David Halloran Lumsdaine, um dos mais destacados teóricos dessa corrente, assinala que a teoria realista do poder e os argumentos fundados nos interesses econômicos e políticos seriam incapazes de abarcar as convicções humanitárias e de explicar por que os governos cooperam e prestam ajuda internacional na promoção do desenvolvimento (Lumsdaine, 1993). Muitos estudos sobre as práticas da cooperação dos países nórdicos empregaram essas lentes teóricas a fim de interpretar a influência dos valores da tradição social-democrata na política de ajuda internacional por eles desenvolvida. Olav Stokke empregou a expressão "humane internationalism" para referir-se aos determinantes da política de ajuda internacional da Dinamarca, Canadá, Países Baixos, Noruega e Suécia (Stokke, 1989).

Contraponto do internacionalismo liberal e construtivista, a visão realista da CID tenderia a ressaltar que nem todas as formas de cooperação são inerente e necessariamente benignas, razão pela qual é importante distinguir entre cooperação como uma forma particular de interação instrumental e os fins perseguidos pela interação cooperativa. ${ }^{11}$

${ }^{10}$ Em 2000, a China anulou uma dívida de 1,5 bilhão de diferentes países africanos; em 2003, anulou mais 750 milhões. Em 2006, assinou acordos comerciais no valor de 60 bilhões. Entre 2000 e 2005, os fluxos de investimentos diretos chineses dirigidos à África totalizaram 30 bilhões, em setores como cobre e cobalto (República Democrática do Congo e Zâmbia), ferro e platina (África do Sul) e madeira (Gabão, Camarões e Congo-Brazaville). Mas a maioria dos investimentos chineses foi para a Nigéria e o Sudão (petróleo, construção do oleoduto) Angola é o principal fornecedor de petróleo para a China (20\%, em 2006, do total importado pela China). Em 2006, 64\% das exportações de petróleo do Sudão foram para a China. Dados a partir de Moyo (2010).

${ }^{11}$ Como lembra James Robinson, a cooperação é um tipo particular de interação que não é nem conflitiva, nem harmoniosa. Trata-se, sociologicamente, de uma das formas mais freqüentes de interação, porém seu grau de complexidade merece análise aprofundada. Na teoria política, a saída encontrada para o dilema de cooperar ou não diante da diferença de interesses produziu pensamentos e tradições distintas, de Maquiavel, Grotius, Hobbes, Locke a Kant (Robinson, 2008, p.71-82). 
Quando cooperam, os Estados são racionais, oportunistas e estratégicos a fim de melhorarem a sua própria condição; agir de modo diferente seria não apenas ingênuo, mas perigoso para a sua sobrevivência e bem-estar (Nelson, 1968). Ademais, as regras da CID não definem, de forma clara e obrigatória, as sanções para os agentes impunes; os ganhos efetivos com a cooperação promovida podem ser até mesmo superiores ao que se mantém com a opção de não cooperar (ênfase nos ganhos absolutos), porém a distribuição desses ganhos é desigual (ênfase realista nos ganhos relativos).

Como sublinharia Huntington (1970, p.175), a obrigação moral diz respeito a ajudar os pobres dos países menos desenvolvidos e não os seus governos, o que faz com que muitos dos programas da cooperação canalizados por meio de organizações privadas possam, na concepção do autor, cumprir mais eficazmente esse dever moral em comparação com estruturas burocráticas públicas, que tenderiam a ser movidas por interesses de política externa. Entre os tipos de benefícios que projetos e financiamentos trariam para o país doador, poderíamos lembrar o acesso a insumos estratégicos (minério, produtos agrícolas, etc.), a obtenção de votos favoráveis no sistema multilateral, a contenção de inimigos ideológicos (a exemplo do comunismo durante a Guerra Fria), a promoção de interesses ligados ao comércio exterior e investimentos, a venda de excedentes de commodities, bem como a imposição de modelos de políticas públicas (ajuste econômico, liberalização do comércio exterior, etc.).

Nesse mesmo sentido da interpretação realista, Hans Morgenthau afirmou que as visões sobre a ajuda externa variam em um amplo espectro político desde a concepção de que a cooperação seria um fim em si mesma, justificável do ponto de vista da moral e, portanto, de forma independente da política externa dos Estados, até, no outro extremo, seus opositores ferrenhos, segundo os quais ela não seria passível de justificação política, haja vista que não serviria nem aos interesses do Estado-doador, nem aos dos países beneficiários. Reconhecendo a diversidade das políticas existen- tes, o autor identifica seis tipos de ajuda externa, sendo que todas dizem respeito à transferência de fundos financeiros, bens e serviços de uma nação para outra: (i) ajuda humanitária; (ii) ajuda para a subsistência; (iii) ajuda militar; (iv) ajuda-suborno (“bribery”); (v) ajuda para obter prestígio; (vi) ajuda externa para o desenvolvimento econômico (Morgenthau, 1962, p.301).

Outro contraponto, a nosso ver não menos relevante, à interpretação liberal sobre o papel da CID nas relações internacionais origina-se da corrente marxista, de alguns teóricos da dependência e de defensores da teoria crítica (Amin, 1976; Halliday, 2007; Hayter, 1971; Molnar, 1975; Kubalkova; Cruickshank, 1989). Tais autores lembrariam que a CID pode ser explicada à luz do materialismo histórico enquanto tentativa de preservação do capitalismo, servindo como ferramenta de manutenção e legitimação da hegemonia dos países centrais do sistema internacional. Antigas colônias, agora emancipadas, poderiam ser mantidas em relações de dependência e de garantia do funcionamento da economia internacional. A ajuda prestada seria condicionada ao respeito de uma gramática mais ampla do capitalismo: não nacionalizar empresas estrangeiras sem que se definam medidas de compensação, não estabelecer regras rígidas acerca da repatriação dos lucros das multinacionais, implementar políticas de ajustamento estrutural, seguir padrões internacionais de estabilidade macroeconômica, assegurar o respeito aos direitos de propriedade (material e imaterial), etc.

Além disso, alguns fatores determinantes do desenvolvimento poderiam não ser afetados favoravelmente pelo influxo de fundos da CID, a exemplo das atitudes econômicas, valores sociais e políticos, bem como objetivos e princípios qualitativos do desenvolvimento (Pankaj, 2005, p.114). A CID também poderia minorar qualitativamente os processos de aprendizagem: quando os recursos são produzidos endogenamente, o país em questão tem a oportunidade de desenvolver os processos de produção, novas habilidades e tecnologias, porém sempre que forem simplesmente importados por meio da ajuda externa, os pro- 
cessos de aprendizado e de desenvolvimento das capacidades locais ficam prejudicados. Cria-se, assim, uma dependência a partir do momento em que o planejamento nos países beneficiários tende a considerar, com segurança, a entrada dos insumos externos, sem a preocupação de produzi-los, por meio de mecanismos de inovação, no plano doméstico. No entanto, como afirma Pankaj (2005, p. 116, tradução nossa), "o desenvolvimento não pode ser logrado sem que, domesticamente, sejam feitos investimentos e avanços em capital humano, progresso científico e tecnológico, construção de infraestruturas básicas e alguma forma de organização industrial".

Percebemos, diante do exposto, que cada uma das correntes teóricas do campo das Relações Internacionais ilumina, com base em premissas filosóficas e pressupostos políticos distintos, alguns dos aspectos da CID em suas articulações com o capitalismo e a política internacional. Cabe a cada analista fazer as suas escolhas, do ponto de vista ontológico e epistemológico. Chamamos a atenção do leitor, porém, para um aspecto que nos parece fundamental: a compreensão profunda das dinâmicas da CID implica não negligenciar, além dos aspectos mencionados acima, os fatores e os atores domésticos dos respectivos países (doadores e beneficiários), que tendem quase sempre a serem deixados de lado pelas correntes teóricas das Relações Internacionais. Por que e como o contexto doméstico conta na compreensão das dinâmicas da CID?

Fundamentalmente porque a política externa e suas agendas de cooperação para o desenvolvimento estão cada vez mais conectadas às demais políticas públicas (domésticas). No Brasil e no mundo, a política externa tem sido, em tempos mais recentes, entendida e analisada à luz das preferências e interesses de uma pluralidade de atores. Diplomatas e militares passaram a ter de se acostumar com a companhia, embora por vezes tímida e nem sempre assídua, de burocratas do setor da saúde (ou da cultura, da educação, do desenvolvimento agrário, etc.), de deputados e senadores (e seus assessores legislativos), prefeitos e governadores, operadores econômicos, líde- res de ONG, movimentos sociais, organismos da mídia e personalidades da academia. Atores tradicionalmente invisibilizados da cooperação internacional passam a ganhar voz no cenário internacional e doméstico, fazendo com que o aumento de interesse e o debate público tendam a conduzir o campo da política externa a um processo lento e gradual de abertura e conflitualidade política (Pinheiro; Milani, 2012). Tal processo depende mais diretamente da existência de impactos distributivos internos que ocorrem quando os resultados da ação externa deixam de ser simétricos para os diversos segmentos sociais, como no caso de decisões sobre a importação de bens, da negociação de acordos comerciais bilaterais ou multilaterais ou ainda da adesão a regimes internacionais. Como afirma Maria Regina Soares de Lima (2000), a política externa reflete não apenas os constrangimentos sistêmicos, provenientes da própria estrutura da ordem internacional, mas também, e principalmente, as estratégias estabelecidas pelos atores domésticos no contexto da distribuição de interesses e preferências no interior do Estado.

Desse modo, opinião pública, disputas eleitorais, instituições domésticas, entre outras variáveis, são relevantes na compreensão das decisões dos Estados em matéria de CID. Esse sempre foi um fenômeno patente nas decisões do governo norte-americano e da USAID, da mesma maneira que a República Federal da Alemanha, ao se tornar um importante doador a partir dos anos 1960, passou a exigir contrapartidas relativas à sua segurança nacional. Com base na doutrina Hallstein, o governo federal alemão demandava (e isso perdurou até os anos 1980) que os países beneficiários de sua ajuda não reconhecessem a República Democrática Alemã. Taiwan também fez esse mesmo jogo diplomático em relação à China, embora sua estratégia tenha se tornado muito menos eficiente depois da visita de Nixon a Pequim e diante dos montantes investidos pelo governo chinês a partir dos anos 1990 no campo da cooperação para o desenvolvimento.

Desde os anos 1990, outras críticas têm sido formuladas fora do campo das Relações Internaci- 
onais. Embora não pretendamos, neste capítulo, abarcá-lo em toda a sua abrangência, o debate sobre o desenvolvimento tem sido retomado no contexto dos precários resultados sociais dos processos de globalização e dos impasses que surgem em todas as perspectivas (econômica, social, cultural, política e ambiental), o que coloca em xeque os pressupostos e os instrumentos que vêm dando suporte à compreensão e à intervenção sobre a realidade do desenvolvimento (Dupas, 2006; Chesnais, 1994; Moraes, 2006; Sachs, 2005). O "desenvolvimento" e o "progresso" prometidos pelos discursos da CID mostraram-se limitados, excludentes e perversos, tal como o ilustra o aumento das desigualdades sócio-econômicas e da exclusão social no plano mundial. Esse contexto expressa uma crise que resulta da inserção desigual dos indivíduos, classes e grupos na sociedade nacional e das nações no sistema internacional, bem como do não cumprimento das promessas do desenvolvimento.

Das diversas abordagens contemporâneas da crise do desenvolvimento, quatro se destacam. A primeira interpretação da crise do desenvolvimento emana daqueles que a associam ao modo capitalista de produção e à sua lógica de acumulação. Portanto, sua superação passa, necessariamente, pela superação desse modo de produzir, distribuir e se apropriar tanto dos resultados da produção quanto do próprio espaço social. Segundo David Harvey (2005), as dimensões geográficas relativas à acumulação do capital e à luta de classes desempenham um papel fundamental na perpetuação do poder burguês e na supressão dos direitos e aspirações do trabalhador, não apenas em lugares específicos, mas também globalmente. Uma segunda abordagem, a crítica antropológica, revela o papel do etnocentrismo e do eurocentrismo na definição dos valores e normas do desenvolvimento enquanto promessa ocidental, ressaltando a natureza histórica e pretensamente universalizante da modernidade. Para essa corrente, os princípios do progresso e da civilização impuseram lógicas e racionalidades como medidas universais para realidades sócio-culturais e contextos históricos muito diversos. Apontam para a necessidade de diálogo com e entre os diferentes povos e o respeito a suas formas de racionalidade (Rist, 1996; Said, 2007).

Uma terceira visão, de linhagem crítica pósmoderna, adverte para a impossibilidade do caráter universal do desenvolvimento, fruto de uma utopia iluminista que acabou favorecendo os interesses das classes dominantes. Nesse sentido, existe hoje um movimento ascendente na Europa da escola pós-desenvolvimentista, segundo a qual, assim como o progresso, o desenvolvimento pode trazer consequências sobre a vida e a liberdade dos homens, camuflando os interesses de diversos grupos de poder que se beneficiam desse mesmo processo. Defendem o pós-desenvolvimento e a pesquisa sobre modos de satisfação (épanouissement) e felicidade coletivas que não busquem apenas o bemestar material, responsável pela desestruturação do meio ambiente e de uma boa parte das relações sociais. Ressaltam assim, a natureza essencialmente plural do desenvolvimento que se desenharia de forma sensivelmente diferente no Norte e no Sul (Latouche, 2004; Escobar, 1994; Rist, 1996). Finalmente, uma quarta abordagem diz respeito à corrente crítica contra-hegemônica que assume os desafios da construção dos valores universais em novas bases. A falta de respostas às questões relacionadas com as desigualdades sociais e a continuidade do tratamento das questões do desenvolvimento, fundamentalmente, na perspectiva econômica, deverão ser a tônica das reivindicações dos movimentos alternativos expressos principalmente no âmbito do Fórum Social Mundial. Os trabalhos oriundos desse debate sinalizam a natureza polissêmica e multidimensional do desenvolvimento. Essa corrente recoloca o debate sobre o papel da economia no desenvolvimento, sobre qual globalização se quer construir e os caminhos possíveis a serem trilhados (Escobar, 1994; Sousa Santos; Meneses, 2010; Santos, 2001). O economista sueco Gunnar Myrdal foi um dos primeiros pensadores a apresentar uma teoria abrangente em que argumentava que o capital seria apenas um dos muitos fatores determinantes do aumento da produção e da renda de uma nação (Myrdal, 1968). 
É evidente que muitos dos pontos explorados por essas abordagens se entrecruzam, como a questão ambiental e a retomada do debate sobre as dimensões e as especificidades dos territórios. Segundo Cássio Hissa, embora a questão ambiental adquira perfil importante nos meios de comunicação em geral, as abordagens dessa temática ainda tendem a privilegiar o paradigma disciplinar, impedindo ou, às vezes, dificultando a expressão das "vozes do mundo", bem como de suas diversidades epistemológicas e ontológicas, desconsiderando, enfim, a diversidade de saberes onde a vida se desenvolve (Hissa, 2008). Acrescenta-se a este olhar a análise da ecologia política que combina uma crítica ao desenvolvimento ambientalmente insustentável com a necessidade de retomar o debate sobre os conflitos distributivos (Martinez-Allier, 2007). A ecologia política parte do princípio de que os problemas ambientais não afetam a todos os indivíduos e grupos sociais uniformemente e afirma que a concentração de riqueza é também o resultado do controle sobre determinados recursos ambientais (Milani, 2008b).

Ainda deveríamos lembrar críticas de outra natureza, desta vez apontadas por vários pesquisadores e intelectuais a partir de um olhar sobre os procedimentos, as regras estabelecidas e a própria realidade do "jogo interno" da cooperação para o desenvolvimento. Segundo Easterly e Pfutze (2008), os dados estatísticos sobre as despesas de cada agência (bilateral e multilateral) são pouco transparentes, principalmente quanto aos custos administrativos (dos doadores e dos beneficiários) e sobre como os fundos são gastos. Além disso, há uma fragmentação dos esforços de cooperação internacional para o desenvolvimento: muitas pequenas agências, alta setorialização nas dimensões enfocadas e nos setores do desenvolvimento e, por via de consequência, falta de coordenação. Um terceiro aspecto analisado pelos autores diz respeito ao direcionamento dos fundos para governos corruptos e por meio de canais institucionais pouco efetivos. Com base nessas críticas, os autores propõem uma classificação de agências e práticas, buscando expressar o que entendem por efetividade, transparência e seletividade, revelando, assim, três tipos de ajuda internacional que, segundo eles, poderiam ser consideradas menos efetivas: a ajuda ligada ("tied aid"), segundo a qual o beneficiário deve comprar bens ou serviços do país doador; a ajuda alimentar, pelos efeitos de substituição que provoca no setor produtivo local; a assistência técnica, que pode acabar por engordar as contas bancárias dos consultores selecionados em detrimento das reais necessidades nacionais de desenvolvimento. Outro aspecto importante por eles mencionado é a ausência de reação e avaliação dos beneficiários às agências bilaterais e multilaterais sobre os resultados e os impactos das práticas. As agências bilaterais mais transparentes, segundo os autores, seriam as do Reino Unido, Suécia e Estados Unidos, enquanto as menos transparentes seriam as do Luxemburgo, Nova Zelândia e Finlândia. Quanto às multilaterais mais transparentes, ressaltam a AID (do Grupo Banco Mundial) e os três bancos regionais de desenvolvimento para Ásia (BAfD), África (BAsD) e América Latina (BID). As multilaterais menos transparentes seriam o UNFPA, o GEF, o BERD, a Comissão Europeia e o Nordic Development Fund (p.35). Também revelam que os dez principais doadores (EUA, Japão, AID, Comissão Europeia, França, Reino Unido, Alemanha, Holanda, Suécia e Canadá) representam cerca de $79 \%$ do total da ajuda, ao passo que as 20 menores agências correspondem a $6,5 \%$. Ademais, alguns países têm duas agências responsáveis pela ajuda, a exemplo dos EUA e do Japão. ${ }^{12}$ No caso particular dos EUA, a fragmentação é estimulada pela presença de mais de 50 agências burocráticas diferentes. No caso de Luxemburgo (dados de 2004), o orçamento era de 141 milhões de dólares repartidos entre 87 países

\footnotetext{
${ }^{12}$ No estudo realizado pelos autores, as agências que melhor bem se classificaram no quesito financiamento a países de renda baixa foram o Nordic Development Fund e o BAfD (constrangimento geográfico), e entre as bilaterais se sobressaíram Luxemburgo e Reino Unido. As que se saíram pior nesse quesito foram os EUA e a Grécia. No que diz respeito à ajuda ligada, à ajuda alimentar e à assistência técnica, entre as agências bilaterais, Irlanda, Noruega, Reino Unido, Portugal e Suíça se saíram muito bem, mas EUA, Grécia e Itália são os países que mais usam esses tipos de ajuda internacional, consideradas pouco efetivas pelos autores.
} 
e 30 setores temáticos distintos, donde resultou que 67 países e 15 setores receberam menos de 1\% do total da ajuda (Brainard, 2007, p.40). Um dos resultados desse processo de fragmentação é o excessivo número de missões de diagnóstico, monitoramento e avaliação realizadas pelas agências financiadoras: os 31 governos dos países mais pobres (principalmente africanos) teriam recebido 10.837 missões de assistência técnica no ano de 2005 (Etienne, 2007, p.897).

Outro aspecto mencionado na literatura é a heterogeneidade dos fluxos financeiros da CID, que dificulta a avaliação de sua efetividade. Tipos diferentes de ajuda externa têm, de maneira muito improvável, efeitos econômicos semelhantes. A comparação entre países-doadores torna-se difícil pelo fato de que os montantes não são desagregados (por setores, por países), ou o são muito raramente: por exemplo, a luta contra a expansão do HIV/AIDS influenciou diretamente a alocação de recursos, mas o mesmo não ocorreu com a educação primária. Isso significa que não basta fazer promessas e assumir compromissos de aumentos da ajuda externa, haja vista que o fundamental seria definir focos em setores e regiões (Mavrotas; Nunnenkamp, 2007, p.591). Focar em educação primária faz sentido para países de renda baixa, mas não parece constituir prioridade para beneficiários de renda média e em estágio mais avançado de desenvolvimento humano. Da mesma forma, a Iniciativa Multilateral de Redução da Dívida, proclamada no G-8 de Gleneagles (no Reino Unido, em 2005), não produziu os mesmos efeitos fiscais em todos os países em desenvolvimento. Projetos elaborados por consultores externos, despesas operacionais excessivas, enfraquecimento de capacidades nos países em desenvolvimento por subtração ou cooptação de peritos, descontinuidade, desconsideração do contexto local, entre outros, são aspectos apontados como problemáticos na concepção e execução de projetos da CID (Correa, 2010, p.212-221).

Do ponto de vista imaterial, a CID pode produzir verdadeiro efeito de "conversão" dos países beneficiários à boa governança, à democracia, ao desenvolvimento das comunidades locais e à luta contra a pobreza, esquecendo o fato de que a promoção da democracia de fora para dentro raramente produz resultados conclusivos. Nesse sentido, alguns autores apontam que aspectos imateriais e sociopolíticos do desenvolvimento têm sido excessivamente privilegiados pelos financiamentos em detrimento de aspectos materiais e produtivos (Etienne, 2007). Por exemplo, a AOD destinada à agricultura foi reduzida em 50\% entre 1986 e 1991, e em 30\% entre 1996 e 2001 (p.899). Sob a presidência de James Wolfensohn, o Banco Mundial teve de ceder às pressões de diferentes ONG ambientalistas e cessou de financiar projetos de grandes barragens, usinas hidrelétricas e projetos de irrigação (p.900).

Não menos importante é o fato de que os Estados doadores podem não cumprir suas obrigações, sem que isso implique quaisquer sanções: não atingem a meta dos 0,7\% do PIB destinados à CID, podem promover a redução dos montantes alocados, realizar mudanças em termos de prioridades, etc. Como lembra Dominguez (2011), os Estados doadores não respeitam seus compromissos, apesar das penalidades defendidas pela Comissão Brandt, em 1980; persistem em associar interesses políticos e comerciais à ajuda prestada (por exemplo, cerca de 30\% da CID, descontada a cooperação técnica, permanece "ligada" à compra de bens e serviços dos Estados doadores), e isso apesar do que fora defendido pela Comissão Pearson em 1969; e proliferam seus programas de cooperação, corroborando a lógica de fragmentação da CID, independentemente do que havia afirmado Harry Truman, no Ponto 4, sobre o desenvolvimento enquanto empresa cooperativa e conjunta dos Estados, da ONU e suas agências especializadas.

Por conseguinte, apesar das recomendações e das críticas construídas ao longo da história da CID, duas "verdades ou mitos" ainda parecem persistir: a primeira, a ideia do desenvolvimento como um caminho linear a ser perseguido a partir de experiências dos países desenvolvidos, e a segunda, a crença de que a aplicação dos conhecimentos disponíveis podem ser transferidos e apli- 
cados de maneira universal. Esses dois princípios partem do pressuposto de neutralidade do desenvolvimento e da ciência e de que o avanço tecnológico traria necessariamente o progresso para todos. A "crença” na neutralidade da ciência e na "universalidade" dos indicadores de desenvolvimento continua a orientar a elaboração de políticas de desenvolvimento tanto no Norte como no Sul. Desconsidera-se a existência de valores sociais e interesses econômicos implícitos na produção do conhecimento científico e tecnológico, bem como, as consequências de sua aplicação em contextos histórico-culturais específicos. Deixa-se de lado, entretanto, a contribuição dos estudos sociais da ciência na definição de estratégias de desenvolvimento (Latour, 2004). Permeia essa visão a concepção de que a produção "científica" do conhecimento leva sempre à eficiência e nega a importância de outras formas de conhecimento e saberes construídos ao longo da história, por diferentes sociedades.

A partir de reflexões críticas acerca desses "mitos universais", alguns estudiosos avançam na construção de novos princípios e conceitos que discutem e desconstroem antigas verdades científicas, baseadas no modelo cartesiano-newtoniano, e buscam dar conta da intrínseca interconectividade das relações da sociedade com a natureza e da complexidade dos processos de desenvolvimento com as mudanças na ordem internacional e a "emergência" de novos Estados promotores da bandeira da CSS, parece impor-se um olhar mais cuidadoso, analítico e empírico sobre essa realidade da cooperação. O que mudaria com a Cooperação SulSul nas relações econômicas, políticas e culturais entre Estados e sociedades em desenvolvimento? Quais seriam as tendências atuais dessa agenda Sul-Sul de cooperação para o desenvolvimento no caso dos seis países selecionados?

\section{COOPERAÇÃO SUL-SUL E POLÍTICA EXTER- NA EM PERSPECTIVA COMPARADA: propos- ta de uma agenda de pesquisas}

As agendas de política externa de vários países em desenvolvimento integram, hoje, estratégias de cooperação sul-sul (CSS) por intermédio de alianças forjadas no seio de organizações multilaterais (comerciais, financeiras, de segurança), de espaços regionais de integração, mas igualmente por meio de projetos de financiamento e cooperação técnica em áreas desde a saúde pública, educação fundamental e não formal, intercâmbio universitário, meio ambiente, desenvolvimento agrícola, cooperação tecnológica e desenvolvimento científico, gestão pública, até projetos de desenvolvimento produtivo, industrial e de infraestruturas. Tais países são considerados potências emergentes (África do Sul, Brasil, China, Índia, México ou Turquia), mas também são chamados "new powers" (Narlikar, 2010), "grandes países periféricos” (Dupas, 1998) ou "rising states" (Alexandroff; Cooper, 2010). Todos são países de renda média que começam a tornar qualitativamente mais densa a sua participação no sistema de cooperação internacional para o desenvolvimento, não mais apenas enquanto beneficiários, mas também como doadores (Hirst, 2009). Atuam em parceria com outros países em desenvolvimento de diferentes regióes do mundo, podendo agir por meio da cooperação bilateral (o que os torna mais diretamente capazes de controlar a agenda) ou da cooperação multilateral (junto a bancos de desenvolvimento ou fundos criados 
para esse fim), como esquematiza o Quadro 3. Segundo dados de 2011, a cooperação desenvolvida por países não membros da OCDE ainda é pequena relativamente aos principais doadores (Estados Unidos, Japão, Alemanha, França), porém representou cerca de 9,3 bilhões de dólares (US) em 2009, ou seja, $6,4 \%$ do total dos fluxos de cooperação pública, sendo que alguns deles, a exemplo da Arábia Saudita (3,2 bilhões de USD) e da China (1,9 bilhões de USD), superaram doadores tradicionais que são membros do Comitê de Ajuda para o Desenvolvimento (OCDE, 2011).

Além disso, a relevância adquirida pela CSS nas políticas externas desses países é concomitante ao papel que passam a desempenhar na agenda política e econômica internacional, particularmente nos processos de reforma da governança global (Banco Mundial, FMI, OMC, G-20 financeiro) e de reconfiguração de alianças regionais e coalizões interregionais (SADC/Southern African Development
Community, UNASUL/União das nações sul-americanas, Fórum IBAS, grupo BRICS, Shanghai Cooperation Organization, G-20). É evidente que os países selecionados apresentam diferenças em termos de desenho institucional de suas políticas de CSS, de comportamento multilateral, tamanho de suas respectivas economias, inserção regional, modelo produtivo e de desenvolvimento, assim como de suas respectivas políticas domésticas, em alguns casos mais pluralistas do que em outros. Por conseguinte, torna-se cada vez mais relevante pensar em perspectiva comparada, tanto teórica quanto empiricamente, essa realidade da política externa de algumas potências emergentes, e isso em função (i) da dupla inserção que possuem nas agendas de cooperação para o desenvolvimento enquanto beneficiários e doadores; (ii) da construção (ou relevância maior atribuída a essa agenda) de uma diplomacia da cooperação sul-sul, por meio de discursos, instituições, projetos, montantes a

Quadro 3: Síntese das políticas de CSS (países selecionados)

\begin{tabular}{|c|c|c|c|c|c|}
\hline $\begin{array}{r}\text { Temas } \\
\text { Países }\end{array}$ & $\begin{array}{c}\text { Va lor } \\
\text { estimado (US) }\end{array}$ & $\begin{array}{c}\text { Agência responsável e data } \\
\text { de criação }\end{array}$ & Foco geográfico & Temas prioritários & $\begin{array}{c}\text { Ênfase: } \\
\text { Multilateral } \\
\text { Bilateral }\end{array}$ \\
\hline $\begin{array}{l}\text { África do } \\
\text { Sul }\end{array}$ & 143 mi. (2010) & $\begin{array}{l}\text { South African Development } \\
\text { Partnership Agency (2012), } \\
\text { sob o Ministério de Relações } \\
\text { Internacionais e Coopeação. }\end{array}$ & África. & $\begin{array}{l}\text { Processos de paz e } \\
\text { construção da } \\
\text { democracia }\end{array}$ & $\mathrm{M}>\mathrm{B}$ \\
\hline Brasil & $\begin{array}{c}\text { Entre } 400 \mathrm{mi} . \\
\text { e } 1,2 \mathrm{bi} \\
(2010)\end{array}$ & $\begin{array}{c}\text { Agência Brasileira de } \\
\text { Cooperação (ABC, 1987), } \\
\text { sob o MRE/Itamaraty. }\end{array}$ & $\begin{array}{l}\text { América Latina, } \\
\text { África e CPLP. }\end{array}$ & $\begin{array}{c}\text { Saúde, agricultura, } \\
\text { educação, gestão } \\
\text { pública } \\
\end{array}$ & $\begin{array}{l}\mathrm{M}>\mathrm{B} \text { (mas } \\
\quad \mathrm{B} \text { ) }\end{array}$ \\
\hline China & $\begin{array}{l}3,9 \mathrm{bi} . \\
(2010)\end{array}$ & $\begin{array}{l}\text { Não. Agenda conduzida } \\
\text { majoritariamente pelo } \\
\text { Ministério do Comércio. }\end{array}$ & África e Ásia. & $\begin{array}{l}\text { Infraestrutura, produção de } \\
\text { recursos energéticos, } \\
\text { desenvolvimento industrial }\end{array}$ & $\mathrm{B}>\mathrm{M}$ \\
\hline Índia & $\begin{array}{l}680 \mathrm{mi} . \\
(2010)\end{array}$ & $\begin{array}{l}\text { Vários anúncios (desde 2007) } \\
\text { de criação de uma agência, } \\
\text { mas a cooperação ainda é } \\
\text { coordenada pelo Min. das } \\
\text { Finanças e MRE. }\end{array}$ & $\begin{array}{l}\text { Países vizinhos } \\
\text { (Afeganistão, } \\
\text { Butão, Nepal) e } \\
\text { África. }\end{array}$ & $\begin{array}{l}\text { Infraestrutura, irrigação, } \\
\text { tecnologia de informação, } \\
\text { formação }\end{array}$ & $\mathrm{B}>\mathrm{M}$ \\
\hline México & $16 \mathrm{mi}^{*}$ (2009) & $\begin{array}{c}\text { Agencia mexicana de } \\
\text { cooperación internacional } \\
\text { para el desarrollo } \\
\text { (AMEXCID, 2011), junto à } \\
\text { SRE. } \\
\end{array}$ & $\begin{array}{l}\text { América Central } \\
\text { (Costa Rica, El } \\
\text { Salvador, } \\
\text { Guatemala) e } \\
\text { Caribe. } \\
\end{array}$ & $\begin{array}{l}\text { Cooperação técnica, } \\
\text { cientifica e } \\
\text { educativa, gestão de } \\
\text { situações de } \\
\text { emergência } \\
\end{array}$ & $\mathrm{B}>\mathrm{M}$ \\
\hline Turquia & $780 \mathrm{mi}$. (2008) & $\begin{array}{c}\text { Turkish International } \\
\text { Cooperation and } \\
\text { Development Agency(TIKA, } \\
\text { 1992), diretamente sob o } \\
\text { gabinete do Primeiro } \\
\text { Ministro. Conta com uma } \\
\text { rede de escritórios nacionais. }\end{array}$ & \begin{tabular}{|c|} 
Ásia (Afeganistão, \\
Paquistão, \\
Cazaquistão, \\
Quirguistão), \\
Oriente Médio, \\
Europa dos Bálcãs \\
e África.
\end{tabular} & $\begin{array}{c}\text { Desenvolvimento social, } \\
\text { serviços e infraestrutura } \\
\text { econômica, cooperação } \\
\text { educativa e cultural (por } \\
\text { meio de ONGs turcas) }\end{array}$ & $M>B$ \\
\hline
\end{tabular}

Fontes: Compilação a partir de dados de AMEXID (www.amexcid.gob.mx); Ayala e Perez (2009); GHSi (2012); IPEA/ABC (2010); Latt (2011); OCDE (www.oecd.org/dac); German Development Institute website; TIKA website.

* Dados disponíveis somente para cooperação técnica. 
partir dos anos 1990/2000; (iii) da relevância estratégica desses países na geopolítica regional e global; (iv) do legado histórico em termos de participação, entre os anos 1950 e 1970, nos debates sobre as relações centro-periferia, não alinhamento, terceiro mundo e nova ordem econômica internacional; e (v) das semelhanças e diferenças que apresentam para fins de uma démarche comparativa (Beasley et al, 2002), conforme esboçamos no Quadro 3.

É importante ressaltar que pensar a CSS no âmbito das respectivas políticas externas desses países já aponta para uma segunda opção de natureza teórica e metodológica: as estratégias de CSS não são dissociadas das decisões relativas à inserção internacional desses Estados (projeção de poder político) e à internacionalização de seus respectivos capitalismos no cenário geopolítico e econômico (projeção de poder econômico regional e global). No caso da África do Sul, por exemplo, a cooperação bilateral é canalizada principalmente pelo Fundo African Renassaince (cerca de $40 \mathrm{mi}-$ lhões de USD em 2008) e aproximadamente 70\% se destina aos países da SADC. No caso da China, sua política de CSS incluiu, em 2009, doações (cerca de $41 \%$ ), empréstimos sem juros (30\% do total) e empréstimos subsidiados (29\%), sendo que 63\% de sua cooperação se dirigiu a países de baixa renda localizados majoritariamente na África (45,7\% dos financiamentos), Ásia (32,8\%) e América Latina $(12,7 \%)$, de acordo com as prioridades chinesas em matéria energética e alimentar. A cooperação econômica indiana, coordenada pelo Departamento de Assuntos Econômicos do Ministério das Finanças, é primordialmente canalizada a países de seu entorno regional e, em segundo lugar, à África. A cooperação técnica indiana, coordenada pela Divisão de Cooperação Técnica e Econômica do MRE, segue o mesmo padrão em termos de orientação geográfica (Zimmermann; Smith, 2011).

Existem, portanto, fatores sistêmicos globais e regionais (geopolíticos, econômicos, relativos à experiência multilateral de cada um desses países) que explicam as prioridades das agendas de CSS dos países mencionados, mas há igualmente uma dimensão doméstica a ser lembrada. Ao inserir o debate sobre a CSS nas agendas da política externa, reafirma-se a noção de que as decisões sobre concepção e implementação das políticas são objeto da barganha entre atores institucionais e não governamentais no plano doméstico. A política burocrática (Allison, 1971) e a legitimação das agendas e atores da CSS (Pinheiro; Milani, 2012) são modelos analíticos que permitem entender, no plano doméstico, como e por que são tomadas decisões sobre CSS. Finalmente, ao analisar a CSS desses países à luz de seus respectivos interesses de política externa, afastamos pressupostos mais idealistas sobre as motivações dos agentes, o que não significa, evidentemente, que suas estratégias de cooperação não possam adotar e desenvolver critérios, normas ou, inclusive, responder a demandas de controles democráticos (prestação de contas, transparência) quanto a seus modos de funcionamento, sempre dependendo, no entanto, da trajetória das relações entre Estado e sociedade em cada contexto analisado.

Historicamente, não seria tarefa simples estabelecer com precisão as origens da CSS, haja vista a variedade de projetos, modalidades de ação e ênfases de cada país. De todas as formas, acreditamos que qualquer esforço nesse sentido deve apontar para os anos 1950, mais concretamente em 1955 com a realização da I Conferência de Países da Ásia e da África em Bandung (Indonésia), como ponto central e marco histórico relevante para o desenvolvimento posterior dessa forma de cooperação entre países em desenvolvimento. A questão central discutida em Bandung visava a influenciar as mentalidades das elites dirigentes nos países do Terceiro Mundo, muitos deles recentemente emancipados, no sentido de deixar de lado suas diferenças em prol de uma plataforma comum de denúncia das calamidades do colonialismo. São os primeiros passos da cooperação política entre países com características semelhantes, inseridos na periferia do sistema internacional. Além disso, também decorreram desses primeiros passos algumas posturas diplomáticas e geopolíticas de distância equilibrada em relação às duas superpotências. A "inspiração" para o movimento dos não alinhados 
surgiu em Bandung, sendo que a fundação do MNA se deu somente em 1961, durante a Conferência de Belgrado.

Haveria, evidentemente, alguns eventos importantes que poderiam ser lembrados como marcos relevantes na história da CSS, por exemplo: a Primeira Conferência das Nações Unidas sobre Comércio e Desenvolvimento (1964); a criação do G-77 nas Nações Unidas e a Nova Ordem Econômica Internacional; a Conferência de Buenos Aires e seu Plano de Ação sobre Cooperação Técnica entre Países em Desenvolvimento (1978); a instalaçao, em 1992, da agência turca de cooperação e desenvolvimento (TIKA); o reestabelecimento, com a mudança terminológica, da Unidade de Cooperação Sul-Sul no âmbito do Programa das Nações Unidas para o Desenvolvimento (1996); a celebração do Primeiro Fórum de Cooperação China-África em Beijing (2000); o Fórum Índia-BrasilÁfrica do Sul (IBAS) em 2003; a celebração do ano da África para a cooperação turca em 2005; o lançamento pelo Brasil de seu primeiro relatório, preparado pelo Instituto de Pesquisas Econômicas Aplicadas (IPEA) e pela Agência Brasileira de Cooperação (ABC), sobre cooperação para o desenvolvimento (2010); a fundação da Agência Mexicana de Desenvolvimento e Cooperação (AMEXID) em 2011; o lançamento, em 2012, do Programa de Cooperação Técnica Descentralizada Sul-Sul do governo brasileiro, com edital com valor global de 2 milhões de USD para projetos concebidos por municípios e estados (2012); o debate entre os BRICS sobre a criação de um banco de desenvolvimento, a partir da iniciativa indiana em 2012, entre outros.

De fato, no contexto da globalização desde os anos 1990, particularmente com a crise econômico-financeira que assola o centro e a periferia do sistema internacional, mas também no âmbito dos debates sobre o futuro das relações Norte-Sul e da cooperação internacional, as políticas de CSS ressurgem de modo claramente associado ao papel renovado de alguns países em desenvolvimento, os mais poderosos global e regionalmente, visando principalmente a alicerçar a ideia de que os países do Sul podem (e devem, vão afirmar alguns discursos de política externa) cooperar com outros países do Sul. ${ }^{13}$ A CSS afirma e busca introduzir uma nova visão do desenvolvimento econômico dos países em desenvolvimento (quanto ao papel do Estado, em matéria de alianças entre países do Sul, quanto ao principio da não intervenção, à defesa da horizontalidade dos programas de cooperação, etc.) e garantir uma inserção internacional diferenciada de alguns países do Sul no diálogo com os países desenvolvidos (Chisholm, L.; Steiner-Khamsi, 2009). Boa parte do argumento político que sustenta a CSS se fundamenta no pressuposto de que países em desenvolvimento podem e devem cooperar a fim de resolver os seus próprios problemas políticos, econômicos e sociais com base em identidades compartilhadas (excolônias, status econômico, experiência histórica, etc.), esforços comuns, interdependência e reciprocidade. Como argumenta Bruno Ayllón Pino (2011, p.274), a CSS destaca-se como fenômeno internacional que atua em duas dimensões,

uma dimensão política que contempla uma modalidade de cooperação entre países que querem reforçar suas relações bilaterais e coligar-se multilateralmente para ganhar poder negociador nos temas e agenda global. A outra dimensão mais técnica em que dois ou mais países adquirem capacidades individuais e coletivas através de intercâmbios cooperativos em conhecimentos tecnologia e know how.

Foi nesse contexto que o discurso oficial e as práticas brasileiras de CSS buscaram, principalmente a partir dos anos 2000, distinguir a cooperação para o desenvolvimento tradicional daquela iniciada e cada vez mais frequentemente realizada pelo Brasil. A Agência Brasileira de Cooperação (ABC), ligada diretamente ao Itamaraty, define

${ }^{13}$ Na nossa concepção, o "Sul”, que nos remete às relações Norte-Sul, seria o que corresponde, no discurso político-diplomático, à periferia e à semiperiferia dos debates sociológicos, estruturalistas e cepalinos. E bem verdade que a noção de "Sul Global", presente em muitos discursos atuais, tende a minorar o lugar político do Norte e do Centro, além de negligenciar as heterogeneidades entre distintas sociedades e economias dos países em desenvolvimento; portanto, preferimos evitá-la em nosso texto. Uma discussão rica e interessante sobre as epistemologias do Sul pode ser encontrada em Souza Santos e Meneses (2010). 
a cooperação técnica como aquela que "constitui importante instrumento de desenvolvimento, auxiliando um país a promover mudanças estruturais nos seus sistemas produtivos, como forma de superar restrições que tolhem seu natural crescimento. Os programas implementados sob sua égide permitem transferir conhecimentos, experiências de sucesso e sofisticados equipamentos, contribuindo assim para capacitar recursos humanos e fortalecer instituições do país receptor, para possibilitar-lhe salto qualitativo de caráter duradouro". ${ }^{14}$ Segundo o IPEA (2010, p.17), a cooperação internacional para o desenvolvimento seria

a totalidade de recursos investidos pelo governo federal brasileiro, totalmente a fundo perdido, no governo de outros países, em nacionais de outros países em território brasileiro, ou em organizações internacionais com o propósito de contribuir para o desenvolvimento internacional, entendido como o fortalecimento das capacidades de organizações internacionais e de grupos ou populações de outros países para a melhoria de suas condições socioeconômicas.

Ambas as agências ressaltam a importância estratégica que a CSS tem assumido nas agendas da política externa brasileira, e se distanciam do con- ceito de ajuda oficial para o desenvolvimento (AOD) da OCDE, uma vez que salientam poderem ser chamadas de cooperação somente as atividades cujos recursos são investidos a fundo perdido e não com, pelo menos, 25\% de concessão (sem necessidade de retorno), como define o CAD da OCDE.

\section{CONSIDERAÇÕES FINAIS}

Como os seis países selecionados concebem e implementam suas políticas externas de CSS? Por meio dessas políticas, assumem liderança regional e os eventuais custos dessa liderança? Compartilham poder decisório com outros países em desenvolvimento no seio de estruturas multilaterais? O que aprenderam a partir das práticas mais tradicionais da CNS? Qual é a experiência acumulada no campo da CSS nos seis países selecionados? Com base em que desenhos institucionais concebem e implementam essa agenda? Quais seriam as áreas temáticas (cooperação técnica, saúde, educação, segurança pública, meio ambiente) e regiões prioritárias (África, América Latina)? Quais seriam as contradições entre interesses pú-

Quadro 4 - Quadro de análise da CSS em perspectiva comparada

\begin{tabular}{|c|c|c|}
\hline Questões & Variável dependente & Variáveis independentes e dimensões \\
\hline $\begin{array}{l}\text { Como os países } \\
\text { selecionados concebem } \\
\text { e implementam suas } \\
\text { políticas externas de } \\
\text { CSS? }\end{array}$ & \multirow{4}{*}{$\begin{array}{l}\text { Perfil da política externa } \\
\text { de CSS dos seis países } \\
\text { selecionados na ordem } \\
\text { pós-1989: África do Sul, } \\
\text { Brasil, China, Índia, } \\
\text { México e Turquia } \\
\text { Natureza da cooperação: } \\
\text { doação, empréstimo, } \\
\text { cooperação técnica; } \\
\text { montantes investidos; } \\
\text { setores e políticas } \\
\text { públicas; ênfase em } \\
\text { cooperação multilateral } \\
\text { ou bilateral } \\
\\
\text { Normas da cooperação: } \\
\text { padrões, valores e } \\
\text { conceitos propostos pela } \\
\text { política de CSS; estudo } \\
\text { de projetos } \\
\text { emblemáticos }\end{array}$} & $\begin{array}{l}\text { Dimensão histórica (variável contextual e formativa): como as } \\
\text { estratégias de CSS foram integradas às agendas de política externa? } \\
\text { Qual é a experiência de cada país em termos de CNS? } \\
\text { (história diplomática e história da política externa, autonomia política } \\
\text { e construção de coalizões, experiência multilateral). }\end{array}$ \\
\hline $\begin{array}{l}\text { Por meio de suas } \\
\text { políticas de CSS, } \\
\text { assumem liderança } \\
\text { regional, aceitam pagar } \\
\text { custos dessa liderança e } \\
\text { compartilham decisão } \\
\text { com outros países em } \\
\text { desenvolvimento? }\end{array}$ & & $\begin{array}{l}\text { Dimensão geopolítica (variável contextual e constitutiva): quais são as } \\
\text { motivações econômicas e os fundamentos geopolíticos para as políticas } \\
\text { de CSS? } \\
\text { (relação com a segurança coletiva regional e global, relação com } \\
\text { processos de integração regional, com o comércio, acesso a mercados e } \\
\text { os investimentos públicos, relação com a internacionalização das } \\
\text { empresas de cada país selecionado) }\end{array}$ \\
\hline $\begin{array}{l}\text { Desafiam ou colocam em } \\
\text { xeque o sistema } \\
\text { tradicional da CNS? }\end{array}$ & & $\begin{array}{l}\text { Dimensão institucional (variável independente): existe uma agência } \\
\text { responsável pela cooperação sul-sul? } \\
\text { (aparato institucional, processo decisório, política burocrática, } \\
\text { ministérios e agências, entidades subnacionais, aspectos da liderança) }\end{array}$ \\
\hline $\begin{array}{l}\text { O que aprenderam a } \\
\text { partir das práticas mais } \\
\text { tradicionais da CNS? }\end{array}$ & & $\begin{array}{l}\text { Dimensão da política doméstica (variável independente): quais são os } \\
\text { principais atores e agendas das políticas de CSS? } \\
\text { (legitimação social, atores não institucionais, opinião pública) }\end{array}$ \\
\hline
\end{tabular}

Fonte: elaboração própria.

${ }^{14}$ Disponível em http://www.abc.gov.br/ct/introducao.asp.

Acesso em 08 de janeiro de 2012. 
blicos e provados, geradas pelos processos concomitantes de internacionalização das empresas dos respectivos países e suas agendas de CSS? Tais questionamentos integram a nossa atual agenda de pesquisa, por meio da qual visamos a produzir resultados que nos permitam um conhecimento mais aprofundado e comparativo da realidade da CSS (vide Quadro 4).

(Recebido para publicação em 07 de abril de 2012) (Aceito em 09 de julho de 2012)

\section{REFERÊNCIAS}

ALEXANDROFF, A. S.; COOPER, A. F. (Org.) Rising states, rising institutions: challenges for global governance. Washington, D. C.: Brookings Institution Press, 2010.

ALLISON, Graham. The essence of decision: explaining the Cuban missile crisis. Boston: Little Brown, 1971.

AMIN, Samir. O desenvolvimento desigual: ensaio sobre as formações sociais do capitalismo periférico. Rio de Janeiro: Forense Universitária, 1976.

AYALA, Citlali; PEREZ, Jorge A. (Org.) México y los países de renta media en la cooperación para el desarrollo: ¿ Hacia dónde vamos? México: Instituto Mora, 2009.

BEASLEY, R.; KAARBO, J.; LANTIS, J.; SNARR, Michael T. (Org.) Foreign policy in comparative perspective: domestic and international influences on state behavior. Washington: CQ Press, 2002.

BRAINARD, Lael. Organizing US Foreign Assistance to meet 21st century challenges. In: LAEL, Brainard (Org.) Security by other means: foreign assistance, global poverty, and American leadership. Washington D.C.: The Brookings Institution Press, 2007. cap. 2.

CHESNAIS, F. La mondialisation du capital. Paris: Syros, 1994. $286 \mathrm{p}$.

CHISHOLM, L.; STEINER-KHAMSI, G. South-South cooperation in education and development. New York: Teachers College Press, 2009.

CORREA, M. Lopes. Prática comentada da cooperação internacional: entre a hegemonia e a busca de autonomia. Brasília: Edição do Autor, 2010.

DEGNBOL-MARTINUSSEN, John; ENGBERGPEDERSEN, Poul. AID Understanding international development cooperation. Londres; New York: Zed Books, 2003.

DOMINGUEZ, Rafael. La crisis de identidad del sistema de ayuda. Documento de discussão. Barcelona: Fundación Carolina, maio de 2011.

DUPAS, Gilberto. A lógica da economia global e a exclusão social. Estudos Avançados, São Paulo, n.34, IEA/USP, set./dez. 1998

DUPAS, Gilberto. O mito do progresso. São Paulo: Editora UNESP, 2006. Rio

EASTERLY, William; PFUTZE, Tobias. Where does the money go? Best and Worst Practices in Foreign Aid. Journal of Economic Perspectives, [S.l.], v.22, n.2, p.29-52, 2008. ESCOBAR, Arturo. Encountering development: the making and unmaking of the third world. Princeton: Princeton University Press, 1994

ETIENNE, Gilbert. Les dérives de la coopération NordSud, vers la fin des chimères? Politique Etrangère, Paris, Institut Français des Relations Internationales, n.4, p.891904, 2007.

GHSi. Global Health Strategies initiatives Shifting paradigm: how the BRICS are reshaping global health and development. 2012. Disponível em: http:// ghsinitiatives.org/downloads/ghsi_brics_report.pdf.

GOTTSBACHER, M.; LUCATELLO, S. (Org.) Reflexiones sobre la ética y la cooperación internacional para el desarrollo: los retos del siglo XXI. México D. F.: Instituto Mora, 2008.

HALLIDAY, F. Repensando as relações internacionais. Porto Alegre: UFRGS, 2007.

HARVEY, D. A brief history of neoliberalism. Chicago: University of Chicago; Center for International Studies, 2005.

HAYTER, Teresa. Aid as imperialism. Londres: Penguin Books, 1971.

HIRST, M. Países de renda média e a cooperação Sul-Sul: entre o conceitual e o político. In: LIMA, M. R. S.; HIRST, M. (Org.). Brasil, Índia e África do Sul: desafios e oportunidades para novas parcerias. São Paulo: Paz e Terra, 2009.

HISSA, Cássio E. V. Saberes ambientais: desafios do conhecimento disciplinar. Belo Horizonte: Ed. da UFMG, 2008.

HUNTINGTON, Samuel P. Foreign Aid for What and for Whom. Foreign Policy, n. 1, 1970 (inverno de 1970-1971), p. 161-189.

IPEA. Instituto de Pesquisa Econômica Aplicada. ABC. Agência Brasileira de Cooperação Cooperação brasileira para o desenvolvimento internacional 2005-2009. Brasília: 2010 .

KAUL, I.; CONCEIÇÃO, P.; LE GOULVEN, K.; MENDOZA, R. U. (Org.). Providing global public goods: managing globalization. Oxford/New York: Oxford University Press; PNUD, 2003.

KAUL, I.; GRUNBERG, I.; STERN, M. A. (Org.) Global public goods: international cooperation in the 21st century. Oxford/New York: Oxford University Press; PNUD, 1999.

KEOHANE, R. O.; NYE, J. Realism and Complex Interdependence. In: LECHNER, Frank J.; BOLI, John. The globalization reader. Oxford (UK): Blackwell, 2000. p.77-83.

KHARAS, H. Can aid catalyze development? In: MAKING development aid more effective. Washington D. C.: The Brookings Institute, 2010. p. 3-9.

KLEIN, M.; HARFORD, T. The market for aid. Washington: The International Finance Corporation; The World Bank Press, 2005.

KUBALKOVA, V.; CRUCISHANK, A. Marxism and international relations. Oxford: Oxford University Press, 1989.

LANCASTER, C. Foreign aid: diplomacy, development, domestic politics. Chicago: The University of Chicago Press, 2007.

LATOUCHE, S. Survivre au développement: de la décolonisation de l'imaginaire économique à la construction d'une société alternative. Paris: Editions Mille et Une Nuits, 2004. 
LATOUR, B. Politiques de la nature: comment faire entrer les sciences en démocratie. Paris: Découverte; Poche, 2004

LATT, J. Mexico as an emerging donor. EDC 2020, $7^{\text {th }}$ Framework Programme, 2011. Disponível em: http:// www.edc2020.eu/fileadmin/publications/EDC2020 Policy Brief $\mathrm{No}_{-} 18_{-}{ }_{-} \mathrm{Mexico} \mathrm{as}_{-}{ }^{-} \mathrm{n}$ __Emerging_Donor_.pdf

LIMA, M. Regina Soares de. Instituições democráticas e política exterior. Contexto Internacional, [S.1.], v.22, n.2, jul./dez. p.265-303, 2000 .

LUMSDAINE, D. H. Moral vision in international politics, the foreign aid regime 1949-1989. Princeton: Princeton University Press, 1993.

MARTINEZ-ALLIER, J. O ecologismo dos pobres. São Paulo: Editora Contexto, 2007.

MAVROTAS, G.; NUNNENKAMP, P. Foreign aid heterogeneity: issues and agenda. Review of World Economics, v.143, n.4, dez. p.585-595, 2007.

MILANI, Carlos R. S. Ecologia política, movimento ambientalistas e contestação transnacional na América Latina. Caderno CRH: Centro de Recursos Humanos da UFBA, Salvador, v.21, n.53, p. 287-301, 2008.

MOLNAR, M. Marx, Engels et la politique internationale. Paris: Gallimard (Idées),1975.

MORAES, R. C. Estado, desenvolvimento e globalização São Paulo: UNESP, 2006.

MORGENTHAU, H. A Political Theory of Foreign Aid. American Political Science Review, v.56, n.2, jun. p.301 309, 1962.

MORIN, E. Por uma reforma do pensamento. In: PENAVEGA, Alfredo; NASCIMENTO, Elimar Pinheiro do. O pensar complexo. Rio de Janeiro: Garamond, 1999. p. 21-34.

MOYO, D. L'Aide fatale. Paris: JC Lattès, 2009.

MYRDAL G. Asian drama: an inquiry into the poverty of nations. New York: Pantheon, 1968.

NARLIKAR, A. New powers: how to become one and how to manage them. New York: Columbia, 2010.

NELSON, J. Aid influence and foreign policy. New York: The Macmillan Company, 1968.

NICOLESCU, B. O manifesto da transdisciplinaridade. Sâo Paulo: Ed. Triom, 2001.

OCDE. Organização de Cooperação e Desenvolvimento $\therefore$ Econômicos. Development co-operation report 2011. Paris: 2011
OlUTAYO, A. O.; OLUTAYO, M. A. O.; OMOBOWALE, A. O. 'TINA', AIDS, and the underdevelopment problem in Africa. Revista de Economia Política, Rio de Janeiro, .28, n.2, p.239-248, abr./jun. 2008

PANKAJ, A. K. Revisiting foreign Aid theories. International Studies, v.42, n.2, p.103-121,. 2005.

PINHEIRO, L.; MILANI, Carlos R. S. Política externa brasileira: as práticas da política e a política das práticas. Rio de Janeiro: Editora da FGV, 2012.

PINO, B. Ayllón. Agentes transformadores da cooperação para o desenvolvimento: poderes emergentes e Cooperação Sul-Sul. Relaciones Internacionales (La Plata), v.40, p.99-119, 2011.

RIST, G. Le développement: histoire d'une croyance occidentale. Paris: Presses de Sciences Po, 1996.

ROBINSON, J. La posibilidad de cooperación. In: GOTTSBACHER, M.; LUCATELLO, S. (Org.). Reflexiones sobre la ética y la cooperación internacional para el desarrollo: los retos del siglo XXI. Cidade do México: Instituto Mora, 2008. p. 68-91.

SACHS, I. Desenvolvimento e cultura. Desenvolvimento da cultura. Cultura do desenvolvimento. Organização e Sociedade, Salvador, Escola de Administração da UFBA, v.12, n. 33, 2005

SAID, E. W. Orientalismo: o oriente como invenção do ocidente. São Paulo: Companhia da Letras, 2007.

SANTOS, M. Por uma outra globalização. São Paulo: Ed. Record, 2001.

SEVERINO, J.-M.; RAY, O. The end of ODA: death and birth of a global public policy. Working Paper Series, [S.l.], Center for Global Development, n.167, mar. 2009, 28 p. Disponível em: www.cgdev.org

SOUSA SANTOS, B.; MENESES, M. P. (Org.). Epistemologias do Sul. São Paulo: Cortez, 2010.

STOKKE, O. (Org.). Western middle powers and global poverty: the determinants of aid policies of Canada, Denmark, the Netherlands, Norway and Sweden. Uppsala: Scandinavian Institute of African Studies (em cooperação com o Norwegian Institute of International Affairs/ Oslo), 1989

ZIMMERMANN, F.; SMITH, K. More Money, More Actors, More Ideas for Development Co-operation. Journal of International Development, v.23, n.5, 2011. Doi: 10.1002/ jid.1795. 


\section{LEARNING WITH HISTORY: critique to the experience of the North-South Cooperation and present challenges to the South-South Cooperation}

\section{Carlos R. S. Milani}

Based on the critical limitations that were pinpointed regarding the historical experience of the North-South Cooperation, (NSC), the main objective of this paper is to analyze some of the dilemmas that the current strategies of SouthSouth Cooperation (SSC) have to face, which were conceived and developed in countries such as Brazil, Mexico, India, China, Turkey or South Africa. The author defends the hypothesis that the differentiation between NSC and CSS is basically empiric, but that it can also be considered in the view of the multilateral legacy of activism in some of these countries and the new economic and political role they play in the international scenario. The argument is based on the fact that since they were and still are NSC beneficiaries, the aforementioned countries should be aware of the risks of reproducing a cooperation model that they have recently criticized. What is unique and special in the practices of the SSC in these countries? What are the risks that the SSC practices would show less solidarity than the promises announced by their leaders and political representatives?

KEY wORDS: International development, NorthSouth Cooperation, South-South Cooperation, South Africa, Brazil, China, India, Mexico and Turkey.

\section{L'HISTOIRE NOUS ENSEIGNE: les critiques de l'experience de cooperation Nord-Sud et les defis actuels de la cooperation Sud-Sud}

\section{Carlos R.S. Milani}

L’objectif principal de cet article, en tenant compte des limitations critiques de l'expérience historique de la Coopération Nord-Sud (CNS), est d'analyser quelques dilemmes auxquels les stratégies actuelles de Coopération Sud-Sud sont confrontées alors qu'elles sont conçues et développées par des pays tels que le Brésil, le Mexique, l'Inde, la Chine, la Turquie ou l'Afrique du Sud. Lauteur part de l'hypothèse que la différenciation entre CNS et CSS est fondamen-talement empirique mais doit cependant être pensée à la lumière de l'héritage d'un activisme multilatéral de certains pays et du nouveau rôle économique et politique qu'ils jouent sur la scène internationale. L'argument se base sur le principe que, du fait d'avoir été (et d'être encore) bénéficiaires de la CNS, ces pays devraient rester attentifs au risque de reproduction d'un modèle de coopération qu'eux-mêmes critiquèrent dans un passé récent. Qu'y aurait-il de singulier et de différent dans les pratiques de la CSS de ces pays? Quels seraient les risques de voir leurs pratiques de CSS moins solidaires que les promesses annoncées par leurs dirigeants et représentants politiques?

Mots-CLÉs: Développement international, Coopération Nord-Sud, Coopération Sud-Sud, Afrique du Sud, Brésil, Chine, Inde, Mexique et Turquie.

Carlos R. S. Milani - Doutor em Estudos do Desenvolvimento. Professor do Instituto de Estudos Sociais e Políticos (IESP), da Universidade do Estado do Rio de Janeiro (UERJ). Coordena o Núcleo de Pesquisa Laboratório de Análise Política Mundial - LABMUNDO/Antena Rio, desenvolvendo pesquisas na área de política externa brasileira, cooperação Sul-Sul e política externa comparada. Suas mais recentes publicações, são: Política externa brasileira: as práticas da política e a política das práticas. Rio de Janeiro: Fundação Getúlio Vargas, 2012; Atores não estatais e trade policy-making no Brasil: análise dos interesses e das estratégias da CEB e da REBRIP. Dados, Rio de Janeiro, v. 55, 2012; International relations and the paradiplomacy of brazilian cities: crafting the concept of local international management. BAR. Brazilian Administration Review, v. 8, 2011. 
